\title{
Successful Endoscopic Removal of a Large Gastric Trichobezoar Causing Gastric Outlet Obstruction in a Female Child
}

\author{
Hadeer Said Allam ${ }^{1}$, Riham Rabie Issa ${ }^{1}$, Mohamed Abo Elfetoh Othman ${ }^{2}$, Mohamed Tarek Youssef ${ }^{2}$ and Ahmad \\ Mohamed Sira ${ }^{1 *}$
}

${ }^{1}$ Department of Pediatric Hepatology, Gastroenterology, and Nutrition, Menofiya University, Egypt

${ }^{2}$ Department of Anesthesia and Intensive Care, Menofiya University, Egypt

Submission: December 12, 2019; Published: January 08, 2020

*Corresponding author: Ahmad Mohamed Sira, Department of Pediatric Hepatology, Gastroenterology, and Nutrition, National Liver Institute, Menofiya University, 32511 Shebin El-koom, Menofiya, Egypt

\begin{abstract}
Bezoar carries a real challenge in its management. Due to lack of suspicion, diagnosis can be delayed until reaching a huge size or presenting by obstructive manifestations. Trichobezoars are the most difficult to treat with most of cases necessitating surgical intervention. Here we present a four-year old female child with a huge gastric trichobezoar. Diagnosis was missed for one month till presenting with gastric outlet obstruction. Upper gastrointestinal endoscopy revealed a huge trichobezoar impacted in the pyloric ring. Initial endoscopic trials of its release from the pylorus were failing. Careful defragmentation using a foreign body forceps was finally successful to remove the whole bezoar, piece by piece, in one endoscopic session. In spite difficult, patient endoscopic approach can be the first modality for removal of large sized gastric trichobezoars.
\end{abstract}

Keywords: Bezoar; Child; Trichobezoar; Endoscopy; Gastrointestinal tract; Psychological troubles; Stomach; Endoscopic fragmentations; Partial intestinal obstruction; Upper gastrointestinal endoscopy; Abdominal ultrasound

\section{Introduction}

Bezoars are constituted of indigestible material located anywhere in the gastrointestinal tract (GIT). They could be missed for long time due to lack of suspicion and overlapping presentation with other causes. They can present by different presentations according to its type, site, and size. Bezoars are usually found in females with underlying psychological troubles [1].

According to composition, bezoars could be trichobezoars, phytobezoars, lactobezoars, pharmacobezoars, or foreign body bezoar. Trichobezoars can form casts in the stomach that can even extend into the duodenum and small intestine forming a Rapunzel syndrome. Gastric bezoar can manifest with abdominal pain, dyspepsia, and gastric outlet syndrome or partial intestinal obstruction. Diagnosis could be by imaging or upper gastrointestinal endoscopy (UGIE) [2].

Treatment of bezoar depends on its type and characters. Trichobezoars are almost always treated by surgical removal. Endoscopic removal usually fails due to compact nature. Previous trials with dissolution using carbonated liquid or endoscopic fragmentations using laser or diathermy failed with little successful cases of small-sized bezoars [3].

\section{Case Report}

A four-year old female child presented with abdominal distention, severe abdominal pain, non-bilious vomiting, and absolute constipation for few days. She was assessed and referred to our department with suspicion of intestinal obstruction. On examination she was conscious, uncomfortable in bed, and pale. She was afebrile, with tachycardia, normal respiratory rate and normal blood pressure. Abdominal examination revealed a large epigastric mass.

Her history dates one month before presentation by intermittent abdominal pain, anorexia, loss of appetite, and occasional vomiting. She had received symptomatic treatment with no improvement of her condition. Past and family histories were irrelevant. Initial investigations showed; microcytic hypochromic 
anemia with a hemoglobin of $9.3 \mathrm{~g} / \mathrm{dl}$, total leucocyte count of $12.7 \times 10^{3} / \mu \mathrm{l}$, and platelets count of $570 \times 10^{3} / \mu \mathrm{l}$; serum sodium and potassium of $134 \mathrm{mEq} / \mathrm{l}$ and $3.5 \mathrm{mEq} / \mathrm{l}$, respectively.

Abdominal ultrasound was unrevealing showing mild free fluid collection and slow peristalsis. X-ray abdomen showed a large gastric mass with distended stomach (Figure 1a). UGIE was decided to aid in the diagnosis of the cause of gastric outlet obstruction. It revealed a large trichobezoar filling the stomach about $16 \times 10 \mathrm{~cm}$ (Figure $1 \mathrm{~b} \& 2 \mathrm{a}$ ) and impacted firmly in the pyloric canal, obstructing the gastric outlet. The first intention was to relieve the gastric outlet obstruction by grasping the proximal end of the trichobezoar with a foreign body forceps and doing traction; which was unsuccessful. At which time we started defragmentation of the bezoar by rapid shaking method using the foreign body forceps with removal of small piece by piece. In spite difficult and time consuming, it was finally successful to remove a large part of the bezoar, at which time its release from the pyloric canal succeeded. It revealed an underlying pyloric ring pressure ulcer (Figure 2D) with short tailing in the duodenum. Continuation of defragmentation, to loosen its compact nature (Figure 2A), and removal of small piece by piece were finally successful to remove the whole trichobezoar, in about 100 endoscopic passes, with the last part removed as a whole large piece (Figure 2B).

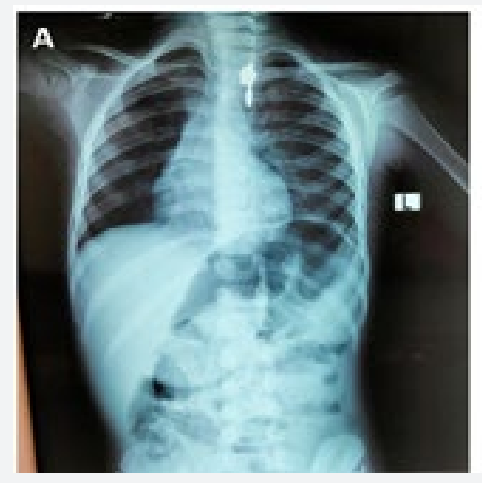

\section{B}

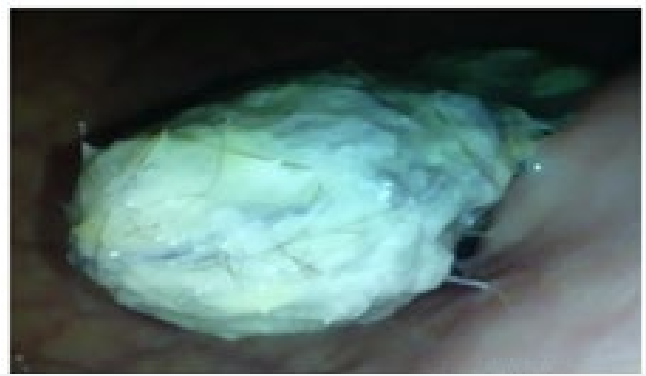

Figure 1: X-ray (A) and endoscopic (B) view of the gastric trichobezoar.
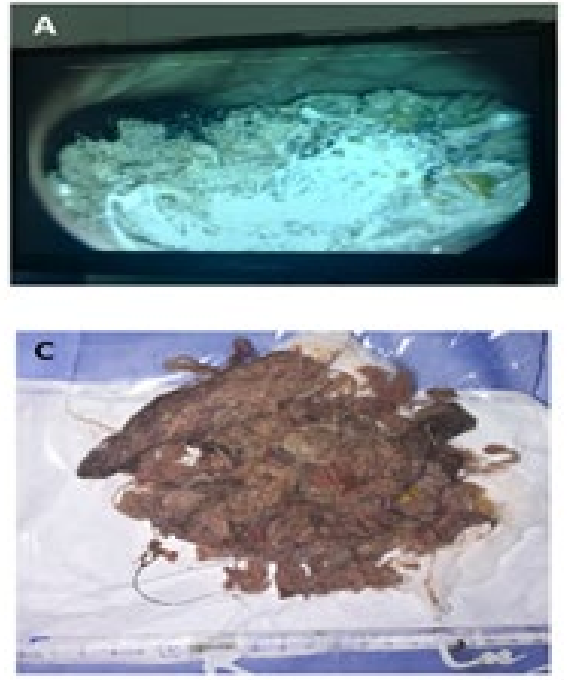

B

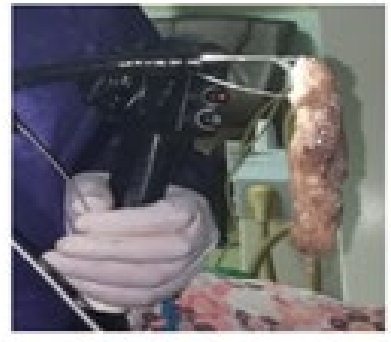

D

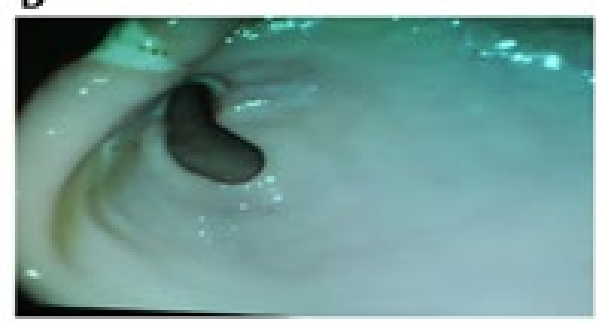

Figure 2: A: The gastric trichobezoar after its loosening by rapid shaking method and removal of much of it. B: The last whole segment removed as one part. C: Collection of most of the pieces of the removed trichobezoar. D: The antrum after removal of the bezoar showing an ulcer on the lesser curvature and another one at the pyloric ring.

Examination of the upper GIT after the trichobezoar removal revealed a multiple shallow gastric ulcers and erosions and another large ulcer at the lesser curvature (Figure 2D). The procedure to remove the whole trichobezoar (Figure 2c) lasted for 5 hours and half during which the patient was anesthetized using the inhalational anesthetic sevoflurane for induction and also for maintenance after intubation using a $5 \mathrm{~mm}$ cuffed endotracheal tube. The child was spontaneously breathing 
with Jackson anesthesia circuit (Anaesthetics India Private Limited, Maharashtra, India). After the end of the maneuver, smooth extubation occurred with full recovery and the child was discharged to the post anesthesia care unite for 2 hours then to the ward. No complications occurred related to the long anesthesia time or the frequent endoscopic passes.

When parent was questioned again it revealed that the girl has a habit of pulling out and swallowing her own hair and recently found to ingest most of the fur of her bunny bear. Dramatic improvement occurred after removal of the bezoar with relief of the pain, vomiting and distention. She started oral feeding few hours after the endoscopy and discharged home within 24 hours of the procedure. She received proton pump inhibitors for one month and iron therapy for two months and was referred to a psychiatrist. Follow up for six months after the procedure showed resolution of her anemia (hemoglobin $=12 \mathrm{~g} / \mathrm{dl}$ ), good appetite and growth, and resolution of her psychiatric troubles with no recurrence of hair ingestion.

\section{Discussion}

Trichobezoars almost always require surgical removal because they consist of large quantities of hair firmly matted together forming compact stony mass. Moreover, trichobezoars may attain large sizes before becoming symptomatic, which render their endoscopic removal difficult [3]. These difficulties made the role of UGIE limited to the diagnostic one. However, there are few reported cases with successfully removed trichobezoar endoscopically. The first reported case was in 1989 by Soehendra [4]. It was a gastric trichobezoar $(15 \times 7 \mathrm{~cm})$ in a 17 -year old girl. The trichobezoar was removed endoscopically with the usage of laser fragmentation in three sessions; 2-3 hours duration, each.

The second case was removed in 1993 by Saeed et al. [5]. It was a gastric trichobezoar in a 54-year old man of $12 \mathrm{~cm}$ in length and 55 gram in weight. They developed a technique by which they retrieved the bezoar intact within 30 minutes in a single endoscopic session. In spite long, its thickness was not reported. Moreover, the larger esophagus and cardiac sphincter size of this adult case makes endoscopic removal easier than that reported in our four-year old child. Aybar \& Safta [6] removed in 2011 a gastric trichobezoar, $8 \times 7 \mathrm{~cm}$ in size, in a 5-year old girl. It was fragmented with hot biopsy forceps and an electrocautery snare into 13 pieces before removal in 25 passes. The procedure time was 3 hours.

Konuma et al. [7] also published in 2011 a successful endoscopic removal of a long gastric trichobezoar extending into the duodenum $(1.8 \times 3.2 \times 34 \mathrm{~cm}$ \& weight of $34 \mathrm{~g})$ in 9 -year old girl. It was retrieved within 15 minutes using a grasper with 5 prolongs and net.

Lastly, Benatta [8] published in 2016 a successful endoscopic removal of a gastric trichobezoar in a 6-year old girl. It was successfully retrieved after endoscopic fragmentation with snare polypectomy and argon plasma coagulation. It was completely removed in 10 pieces after 15 passes. In spite of the previous reporting of different defragmentation methods like argon and diathermy, we didn't use any for fear of complications owing to the unknown contents of this huge trichobezoar. Raval \& Weiner [9] in 2005 reported a case of an apparent explosive event during removal of a gastric trichobezoar when electrocautery was used. This was thought to be caused by gas production in the GIT caused by the decomposing trichobezoar.

Interestingly, in our reported case the skillful anesthesia team helped greatly to accomplish this long duration of anesthesia without any complication with good securing of the airway. Esmaili et al. [10] reported a 17-year old girl with a large trichobezoar ball filled the entire stomach cavity which was divided into smaller pieces. While the removal of the bezoars was being done with endoscopic forceps, a huge trichobezoar ball compressed the upper airway and lead to cyanosis and respiratory arrest.

So, it was apparent that endoscopic removal of trichobezoar is not without a risk. On the other hand, Gulerman et al. [3] reported a 13-year old girl with a gastric trichobezoar $(15 \times 11$ $\mathrm{cm}$ ) in which introduction of oral Coca-Cola for 3 weeks and endoscopic fragmentation failed to remove it. Finally, it was removed surgically. To the best of our knowledge, our reported case is not only the largest trichobezoar that could be successfully retrieved endoscopically in one session, but also in the youngest child. The skillful anesthesia work constituted a cornerstone for the accomplishment of this long-duration maneuver without any complications.

\section{Conclusion}

In conclusion, endoscopic extraction of large sized trichobezoar is possible, but requires much patience, experience, team cooperation, and consideration of different modalities of bezoar defragmentation.

\section{Acknowledgment}

We acknowledge National Liver Institute, Menofiya University for funding this work. We would like to thank the nursing staff of the endoscopy unite and the residents and nursing staff of the Pediatric Hepatology, Gastroenterology, and Nutrition Department for their contribution.

\section{References}

1. Khan S, Khan IA, Ullah K, Khan S, Wang X, et al. (2018) Etiological aspects of intragastric bezoars and its associations to the gastric function implications: A case report and a literature review. Medicine (Baltimore) 97(27): e11320.

2. Nour I, Abd Alatef M, Megahed A, Yahia S, Wahba Y, et al. (2019) Rapunzel syndrome (gastric trichobezoar), A rare presentation with generalised oedema: case report and review of the literature. Paediatr Int Child Health 39(1): 76-78. 
3. Gulerman F, Guven B, Demir S, Ozmen I (2019) How should trichobezoar be treated in children? Turk J Gastroenterol 30(7): 660-661.

4. Soehendra N (1989) Endoscopic removal of a trichobezoar. Endoscopy 21(4): 201.

5. Saeed ZA, Ramirez FC, Hepps KS, Dixon WB (1993) A method for the endoscopic retrieval of trichobezoars. Gastrointest Endosc 39(5): 698700.

6. Aybar A, Safta AM (2011) Endoscopic removal of a gastric trichobezoar in a pediatric patient. Gastrointest Endosc 74(2): 435-437.

7. Konuma H, Fu K, Morimoto T, Shimizu T, Izumi Y, et al. (2011) Endoscopic retrieval of a gastric trichobezoar. World J Gastrointest Endosc 3(1): 20-22.
8. Benatta MA (2016) Endoscopic retrieval of gastric trichobezoar after fragmentation with electrocautery using polypectomy snare and argon plasma coagulation in a pediatric patient. Gastroenterol Rep (Oxf) 4(3): 251-253.

9. Raval MV, Weiner TM (2005) Beware of the flaming hairball--a brief review and warning. J Pediatr Surg 40(4): E37-38.

10. Esmaili MR, Abbasi HR, Baradaranfar MH (2011) Respiratory arrest due to airway obstruction following endoscopic removal of Trichobezoar. J Pak Med Assoc 61(7): 700-701.

\section{Your next submission with JuniperPublishers will reach you the below assets}

- Quality Editorial service

- Swift Peer Review

- Reprints availability

- E-prints Service

- Manuscript Podcast for convenient understanding

- Global attainment for your research

- Manuscript accessibility in different formats

( Pdf, E-pub, Full Text, audio)

- Unceasing customer service

Track the below URL for one-step submission https://juniperpublishers.com/online-submission.php 